\title{
Association of common medical comorbidities with early renal damage in the Chinese tropics with essential hypertension
}

Yuzhuo Zhang ${ }^{1 \dagger}$, Ying Zhao ${ }^{1 \dagger}$, Chenglu Wei ${ }^{1+}$, Yongrong $\mathrm{Li}^{1 \dagger}$, Hira Aslam ${ }^{1}$, Qingmin Feng ${ }^{1}$, Qing Huang ${ }^{2}$, Yu Zheng ${ }^{1}$, Feifen L $v^{1}$, Wei HaO ${ }^{3}$ and Jike $\mathrm{Li}^{1,3^{*}}$

\begin{abstract}
Background: Urine albumin/creatinine ratio (UACR) is an important marker of early renal damage (ERD) caused by hypertension. Recent studies showed that blood pressure was a significant inverse association with temperature and climate. The purposes of our study were sought to explore the association of common medical comorbidities with ERD, and find independent risk factors to ERD in Chinese tropics with essential hypertension.

Methods: From January 2018 to December 2019, we assessed UACR in a total of 599 hypertensive Chinese Hainan patients. We defined ERD as a UACR between $30 \mathrm{mg} / \mathrm{g}$ and $300 \mathrm{mg} / \mathrm{g}$. We analysed differences between qualitative variables using the chi-squared $\left(X^{2}\right)$ test. We calculated correlations between UACR and age, hypertension duration $(\mathrm{HD})$, systolic blood pressure (SBP), and diastolic blood pressure (DBP) using the Spearman's rho test. To determine the odds ratio (OR), we evaluated binary logistic regression models.

Results: Among the 599 patients, 281 (46.9\%) were found to have ERD. ERD and factors related to sex, body mass index (BMI), and SBP did not differ significantly (all, $p>0.05$ ). Our main findings showed that age, $H D$, and DBP were associated with ERD ( $p<0.01$, respectively). Furthermore, age $\geq 65$ years, $H D \geq 10$ years, DBP $\geq 90 \mathrm{mmHg}$, $S B P \geq 160 \mathrm{mmHg}$, and diabetes differed significantly according to ERD status ( $p<0.05$, respectively). In multivariate analysis using stepwise regression, age $(\mathrm{OR}=1.468), \mathrm{DBP}(\mathrm{OR}=1.853)$, and diabetes $(\mathrm{O}=2.031)$ were significant independent predictors of ERD. The area under the receiver operating characteristic (ROC) curve was 0.677 , and the sensitivity and specificity of the optimal cut-off value were 44.5 and $81.1 \%$, respectively.

Conclusions: Common medical comorbidities are associated with ERD; age, DBP, and diabetes are independent risk factors for ERD in patients with essential hypertension who live in the Chinese tropics. Early monitoring of the UACR, as well as control of blood glucose and DBP, can effectively delay ERD.
\end{abstract}

Keywords: Chinese tropics, Early renal damage, Essential hypertension, Urine albumin/creatinine ratio

\footnotetext{
*Correspondence: jike0335@163.com

${ }^{\dagger}$ Yuzhuo Zhang, Ying Zhao, Chenglu Wei and Yongrong Li contributed equally to this work.

${ }^{3}$ Cardiovascular Department, Xi'an Hospital of Traditional Chinese Medicine, No.69, Fengcheng 8th Road, Weiyang District, Xi'an City 710021, Shaanxi Province, China

Full list of author information is available at the end of the article
}

\section{Background}

Hypertension is a risk factor for cardiovascular disease and chronic kidney disease (CKD) [1]. According to the China Hypertension Survey (2012-2015), 23.2\% ( $\approx 244.5$ million) of the Chinese adult population ( $\geq 18$ years) had hypertension during that time period; it is the leading 
modifiable risk factor for coronary heart disease (CHD) and represents the top cause of death in China [2]. Hypertensive nephropathy is the second leading cause of CKD [3]. However, if early renal damage (ERD) is intervened in as early as possible, the renal function of patients with hypertension will obtain better protection. The indexes of ERD include homocysteine, $\beta 2$-microglobulin, cystatin$\mathrm{C}$, serum creatinine, angiotensin-II, microalbuminuria, and urine albumin/creatinine ratio (UACR), yet among those indexes, the level of UACR is relatively high reproducible for clinical practice, and less influenced by urine volume, time, or diet value [4].

For a long time, uncontrolled hypertension could lead to renal failure, a marker of ERD through UACR testing $[5,6]$. Moreover, the UACR, measured in a spot urine sample, is highly correlated with 24-h urine albumin excretion as a predictor of the development and progression of diabetic and non-diabetic renal diseases, as well as of incident hypertension and cardiovascular mortality [7-9]. UACR is little affected [4], while several aspects such as temperature and climate remain uncertain and await elicitation. Currently, hypertensive patients in North China have higher levels of blood pressure than those in the south [10]; one possible cause may be seasonal variation. Multiple studies have indicated that seasonal variation could affect hypertension in Western or Chinese populations [11-13]. Hainan island is located in the southernmost part of the country, where the annual average temperature ranges from $22.5 \sim 25.6^{\circ} \mathrm{C}$, and there is non-significant temperature variation in the tropical, oceanic climate. Previous studies on hypertension have mainly focused on mainland China; data on China's tropical islands related to the detection and control of hypertension are absent. Thus, we aimed to explore the association of common medical comorbidities with ERD, and to identify independent risk factors for ERD with essential hypertension in the Chinese tropics, eventually providing new data for local public health authorities.

\section{Methods}

\section{Study design and participants}

From January 2018 to December 2019, we selected 599 hypertensive patients at both outpatient and inpatient department based on inclusion and exclusion criteria in the First/Second Affiliated Hospital of Hainan Medical University. We included patients if they had newly diagnosed hypertension by measured systolic blood pressure (SBP) $\geq 140 \mathrm{mmHg}$ and/or diastolic blood pressure (DBP) $\geq 90 \mathrm{mmHg}$ three times on different days, or had suffered from hypertension and were taking blood pressure medication. We excluded patients who took high doses of vitamin $\mathrm{C}$ in the previous $10 \mathrm{~h}$; engaged in intense exercise in the previous $24 \mathrm{~h}$ period; stood for a prolonged period over $6 \mathrm{~h}$; had a fever or infection (especially in the urinary system); were menstruating or pregnant; had a history of primary/secondary renal disease, blood system diseases, malignant tumours, connective tissue disease, severe hepatic insufficiency, hyperthyroidism, or chronic heart failure; or had significant proteinuria $(>150 \mathrm{~m} / 24 \mathrm{~h})$, which can be induced by all kinds of diseases.

\section{Hypertension diagnosis}

All patients who met the diagnostic criteria for hypertension had an SBP $\geq 140 \mathrm{mmHg}$ or a DBP $\geq 90 \mathrm{mmHg}$ in the sitting position after $5 \mathrm{~min}$ of rest, as determined by the general practitioner in triplicate; we also included those taking antihypertensive drugs.

\section{UACR monitor}

To monitor the UACR, all urine specimens were supplied in the morning. We gauged urine albumin concentration and urinary creatinine with Clinitek Strips (dry chemistry assay, ACON Biotech, China). The colour appeared after letting the Clinitek Strips stand for $60 \mathrm{~s}$, and we read the values of microalbuminuria and creatinine via a visual method as compared to the chromatogram (Figs. 1 and 2). Finally, according to the interpretation of the test paper, we found the corresponding UACR value to be in the UACR reading metre (Fig. 3). We divided all subjects into two groups: no ERD $(n=318)$ with a UACR of $0-29 \mathrm{mg} / \mathrm{g}$, and ERD $(n=281)$ with a UACR of $30-300 \mathrm{mg} / \mathrm{g}$.

\section{Covariates}

We measured body mass index (BMI), daytime SBP, and daytime DBP. We recorded sex, age, hypertension duration (HD), diabetes, CHD, and stroke. We diagnosed diabetes using medical history if the patient was under antidiabetic treatment, or based on two or more fasting or 2-h post-meal plasma glucose determinations of $\geq 7.0 \mathrm{mmol} / \mathrm{L}(126 \mathrm{mg} / \mathrm{dL})$ and $\geq 11.1 \mathrm{mmol} / \mathrm{L}(200 \mathrm{mg} /$ $\mathrm{dL}$ ), respectively. BMI $<24$ is represented as the normal range.

\section{Statistical analysis}

Continuous variables are presented as the means \pm standard deviations (SD); categorical variables are shown as percentages. We performed statistical analysis of quantitative variables using an independent $\mathrm{t}$-test, and we analysed the differences between qualitative variables via the chi-squared $\left(\chi^{2}\right)$ test. Since the UACR is an ordinal scale, we calculated correlations between UACR and various factors (age, HD, SBP, DBP) with Spearman's rho test. To determine the odds ratio (OR) of ERD, we evaluated binary logistic regression models. We performed a 


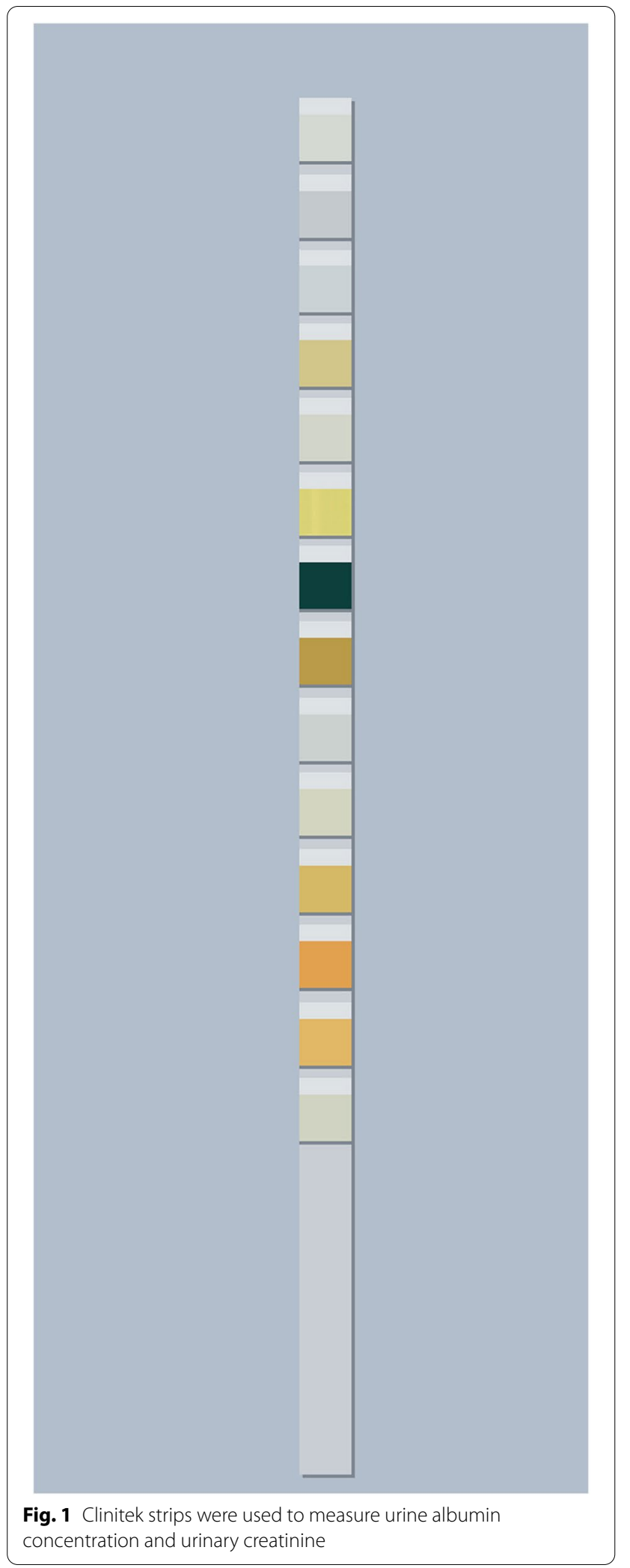

binary logistic regression analysis using SPSS software, version 19.0 (Copyright 1989-2010 Inc., IBM company, IL, USA; ibm.com/cn-zh/analytics/spss-statistics). We considered $p<0.05$ to be statistically significant. The OR indicates the ERD risk of subjects with higher values compared to those with lower values; $95 \%$ confidence intervals (CIs) were reported in the multivariate logistic regression models. For the detailed analysis process, we referenced the work of Lavanderos [14]. To further verify the optimal cut-off value, we calculated it for ERD using the receiver operating characteristic (ROC) curve methodology, described elsewhere [15].

\section{Results}

\section{Basic characteristics}

Of all 599 hypertensive patients, 281 (47\%) had ERD. There were no differences in male sex, BMI, SBP, or antihypertensive drug $(p>0.05)$. Clearly, the age of onset was higher in the ERD group than in the non-ERD group $(61.239 \pm 11.706$ vs. $64.081 \pm 12.352, p=0.004)$, and the same as in the DBP $(81.940 \pm 11.888$ vs. $85.348 \pm 13.660$, $p=0.001)$. Moreover, the ERD had a longer HD $(6.372 \pm 4.352$ vs. $7.650 \pm 5.630, p=0.002)($ Table 1$)$.

\section{Correlation analysis}

We used Spearman's rho test to analyse correlations between ERD and related variables (Fig. 4). There were significant Spearman correlations between ERD and age $(r=0.12, p=0.003), \mathrm{HD}(r=0.115, p=0.005)$, and DBP $(r=0.118, p=0.004)$. The Spearman correlation between ERD and SBP was not significant.

\section{Single factor analysis}

To screen for significant, independent, qualitative variables-including sex, age, BMI, HD, DBP, SBP, and combined disease (CHD, diabetes, stroke) - we employed the $\chi^{2}$ test. Compared with no ERD, ERD was associated with age $\left(<65\right.$ y vs. $\left.\geq 65 y, x^{2}=17.064, p<0.001\right), H D(<10 y$ vs. $\left.\geq 10 \mathrm{y}, \chi^{2}=4.441, p=0.035\right), \operatorname{DBP}(<90 \mathrm{mmHg}$ vs. $\geq$ $\left.90 \mathrm{mmHg}, X^{2}=5.521, p=0.019\right)$, SBP $(<160 \mathrm{mmHg}$ vs. $\left.\geq 160 \mathrm{mmHg}, x^{2}=4.412, p=0.036\right)$ and diabetes status $\left(x^{2}=7.229, p=0.007\right)$, which were significantly different according to the presence of ERD. There was no significant difference between ERD and sex, BMI, CHD, or stroke $(p>0.05)$ (Table 2).

\section{Binary logistic regression model analysis}

To evaluate the weight of the dependent variable and to correct the interaction effect among the above variables, we used a binary logistic regression model for analysis. As outlined in Table 3, age, DBP, and diabetes had statistically significant results for predictors of ERD, since the risks of ERD included age ( $<65 \mathrm{y}$ vs. $\geq 65 \mathrm{y}, \mathrm{OR}=1.468)$, 


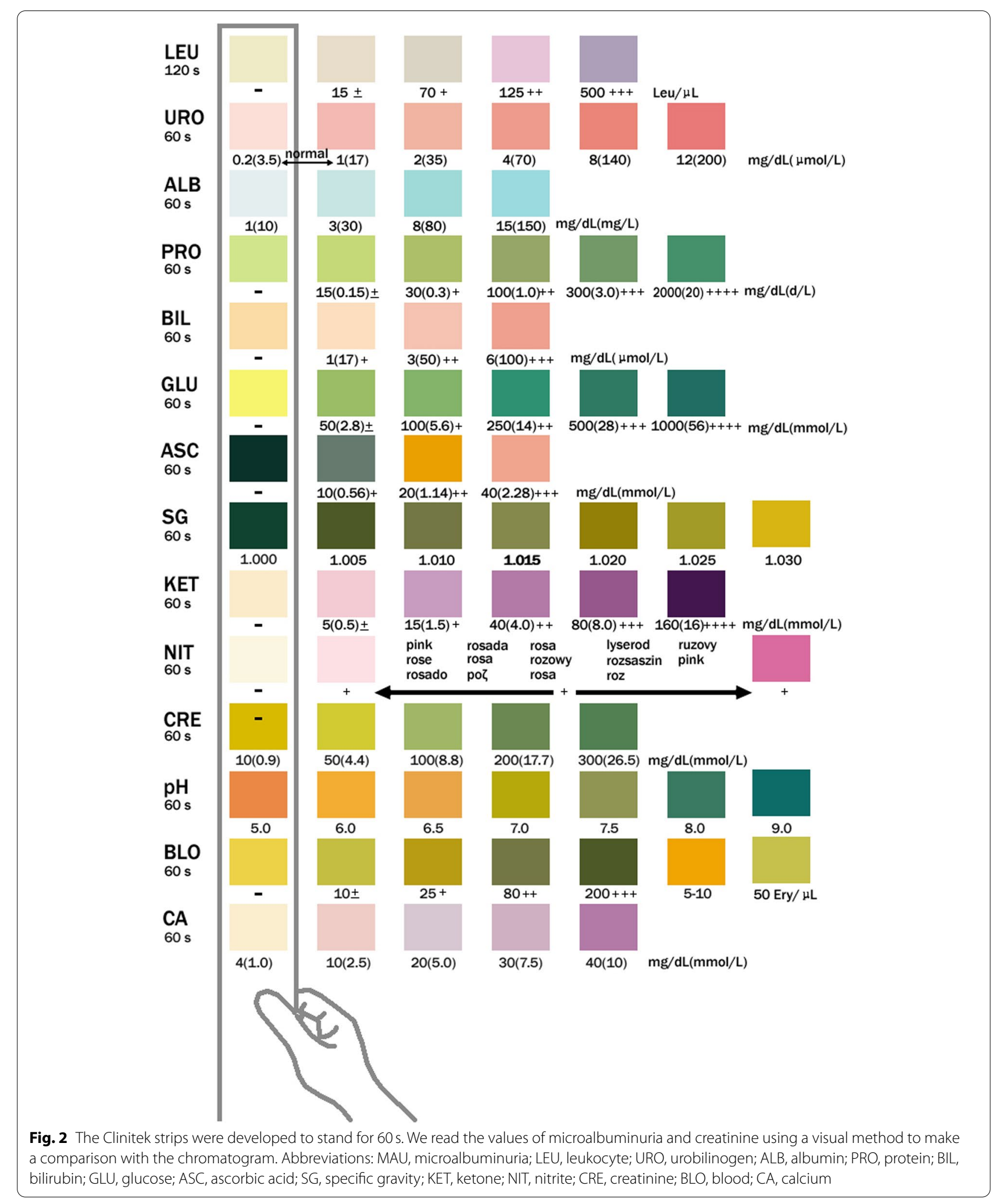




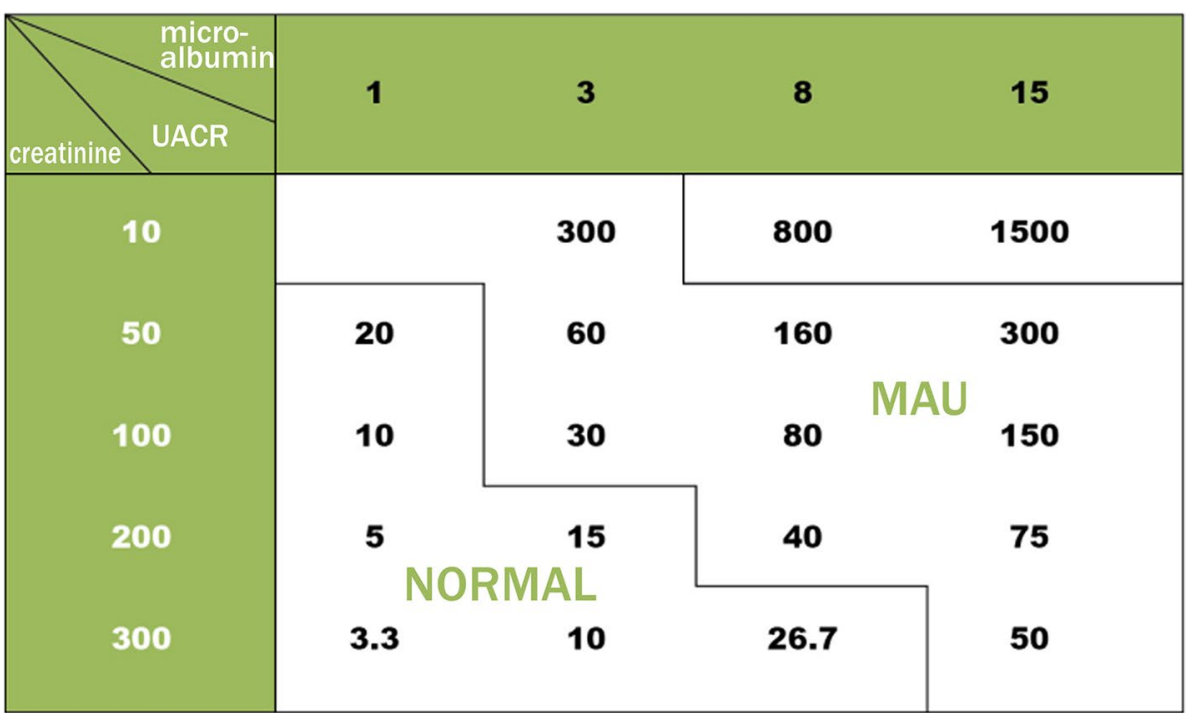

Fig. 3 According to the test paper, the UACR value is found in the UACR reading metre. Note: the unit of microalbuminuria and urinary creatinine is $\mathrm{mg} / \mathrm{dl}$, and the unit of UACR is $\mathrm{mg} / \mathrm{g}$. Abbreviations: UACR, urine albumin/creatinine ratio

Table 1 Baseline characteristics of patients with essential hypertension in the Chinese tropics

\begin{tabular}{llll}
\hline Parameter & No ERD $(\boldsymbol{n}=\mathbf{3 1 8})$ & ERD $(\boldsymbol{n}=\mathbf{2 8 1})$ & $\boldsymbol{P}$ \\
\hline Age $(\mathrm{y})$ & $61.239 \pm 11.706$ & $64.081 \pm 12.352$ & $0.004^{*}$ \\
Male sex (\%) & $152 / 318(47.799 \%)$ & $123 / 281(43.772 \%)$ & 0.328 \\
BMI (kg/m2) & $24.026 \pm 2.827$ & $24.433 \pm 2.800$ & 0.087 \\
HD (y) & $6.372 \pm 4.352$ & $7.650 \pm 5.630$ & $0.002^{*}$ \\
SBP $(\mathrm{mmHg})$ & $138.623 \pm 19.584$ & $141.473 \pm 22.540$ & 0.098 \\
DBP $(\mathrm{mmHg})$ & $81.940 \pm 11.888$ & $85.348 \pm 13.660$ & $0.001^{*}$ \\
Antihypertensive drug & $1.450 \pm 0.657$ & $1.505 \pm 0.677$ & 0.308 \\
\hline
\end{tabular}

Continuous variables are presented as the means \pm standard deviations (SD); categorical variables are shown as percentages

Abbreviations: ERD Early renal damage, BMI Body mass index, HD Hypertension duration, SBP Systolic blood pressure, DBP Diastolic blood pressure.

${ }^{*} p<0.05$ vs no ERD

DBP $(<90 \mathrm{mmHg}$ vs. $\geq 90 \mathrm{mmHg}, \mathrm{OR}=1.853)$ and diabetes $(\mathrm{OR}=2.031)$. Although $\mathrm{HD}$ and SBP were significantly different in the $\chi^{2}$ test, they could not become independent predictors of ERD with binary logistic regression model analysis. Therefore, age, DBP, and diabetes were independent risk factors for essential hypertension in patients who suffered from ERD.

\section{Defining cut-off values}

We employed ROC curves to analyse the relationship between ERD and risk factors (age, DBP, and diabetes). The area under the ROC curve was 0.677 (95\% CI: 0.633$0.720, p<0.001)$. We chose the optimal cut-off value of $\geq 0.551$; the sensitivity and specificity of the optimal cutoff value were 44.5 and $81.1 \%$, respectively (Fig. 5).

\section{Discussion}

Hypertensive renal damage caused by uncontrolled blood pressure alters renal structure and function, and is the second most important cause of CKD after diabetes [16], which seriously threatens patients' health and lives. Therefore, the identification and intervention of ERD are urgently needed to delay the progression of CKD. UACR has been used to identify sensitive indexes of ERD that reflect not only glomerular basement membrane injury but also vascular endothelial structure and dysfunction; these are associated with morbidity and mortality [17]. Measurement of UACR is recommended in all hypertensive patients (ESC Classes of recommendations: IB) [18]. Because of its feasibility and ease of operation, the UACR measurement is widely used in the clinical diagnosis and monitoring of ERD. Controlling hypertension effectively is helpful in reducing UACR levels, which is an extremely important method to slow down the progression of ERD caused by hypertension.

We initially observed the relationship between UACR and ERD in patients with hypertension living in the tropics of China. In our study, $46.7 \%$ were from the outpatient department. To ensure the consistency of blood pressure measurement and UACR detection time, we gauged daytime blood pressure. Our research demonstrated that DBP over $90 \mathrm{mmHg}$ is an independent risk factor for predictors of ERD. Our results indicated that high DBP is associated with increased cardiovascular 


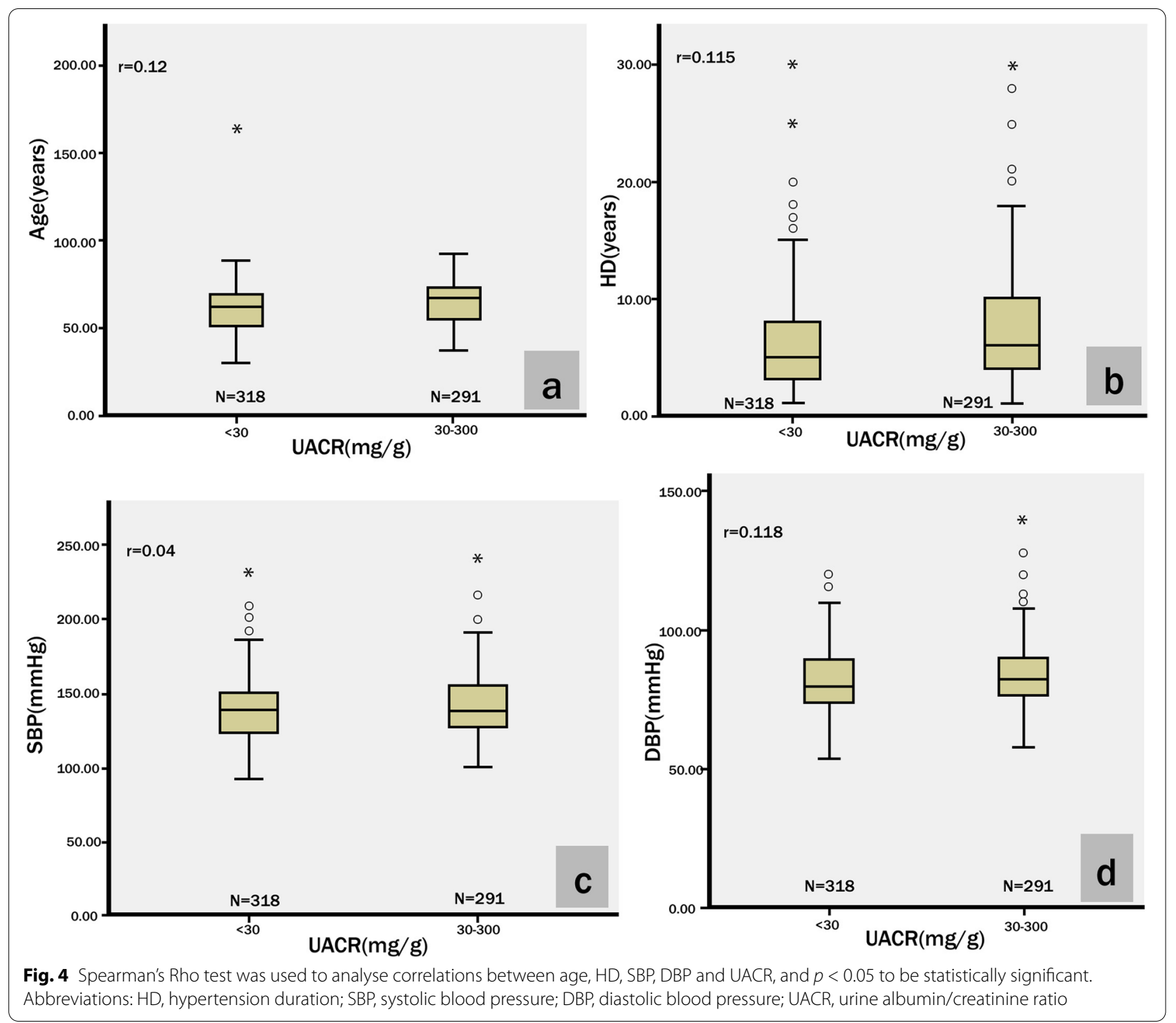

risk and is more commonly elevated in younger individuals ( $<65$ years). The Framingham heart study signalled that DBP tends to decline from midlife as a consequence of arterial stiffening [19], and in middle-aged and older people, increased pulse pressure (the difference between SBP and DBP values) has additional adverse prognostic significance [20]. DBP decreased by $10 \mathrm{mmHg}$ or less than $75 \mathrm{mmHg}$ is associated with the reduction of age-related stroke and ischemic heart disease [21]. DBP reflects the magnitude of peripheral vascular resistance, which is affected by heart rate and the elasticity of the arteriole wall, and is related to the compliance of arteries; moreover, strengthening peripheral arterial vascular resistance leads to an increase in DBP [22]. Target organ injury caused by SBP mainly consists of left ventricular hypertrophy and enlargement, while systemic arteriolar lesions are primarily caused by an increased wall/cavity ratio and reduced lumen diameter, resulting in ischaemia of target organs such as the heart, brain, and kidneys [22]. Therefore, the effect of DBP on renal injury is more notable. Patients with early hypertension and renal injury should more strictly control DBP and reduce peripheral resistance to effectively delay the progression of renal vascular injury. However, there is also the undeniable fact that SBP is closely tied to ERD. Our findings revealed that high SBP $(\geq 160 \mathrm{mmHg}$ ) differs significantly from ERD. Hence, we speculate that higher SBP may be associated with ERD defined by increased UACR of 30 to $300 \mathrm{mg} / \mathrm{g}$. However, the levels of DBP and SBP have received much attention, and are significantly correlated with the degree 
Table 2 The single factor analysis of $x^{2}$ test was used on ERD

\begin{tabular}{|c|c|c|c|c|c|}
\hline Factors & Parameter & No ERD $(n=318)$ & $\operatorname{ERD}(n=281)$ & $x^{2}$ & $P$ \\
\hline \multirow[t]{2}{*}{ Sex } & Male & $152(55.3 \%)$ & $123(44.7 \%)$ & & \\
\hline & Female & $166(51.2 \%)$ & $158(48.8 \%)$ & 3.477 & 0.323 \\
\hline \multirow[t]{4}{*}{ Age (y) } & $<55$ & $96(57.8 \%)$ & $70(42.2 \%)$ & & \\
\hline & $\geq 55$ & $222(51.3 \%)$ & $211(48.7 \%)$ & 2.074 & 0.150 \\
\hline & $<65$ & $194(61.0 \%)$ & $124(39.0 \%)$ & & \\
\hline & $\geq 65$ & $124(44.1 \%)$ & 157 (55.9\%) & 17.064 & $<0.001^{*}$ \\
\hline \multirow[t]{2}{*}{ BMI (kg/m2) } & $<24$ & $159(58.0 \%)$ & $115(42.0 \%)$ & & \\
\hline & $\geq 24$ & $147(50.3 \%)$ & $145(49.7 \%)$ & 3.363 & 0.067 \\
\hline \multirow[t]{2}{*}{$\mathrm{HD}(\mathrm{y})$} & $<10$ & $248(55.6 \%)$ & $198(44.4 \%)$ & & \\
\hline & $\geq 10$ & $70(45.8 \%)$ & $83(54.2 \%)$ & 4.441 & $0.035^{*}$ \\
\hline \multirow[t]{2}{*}{$\mathrm{DBP}(\mathrm{mmHg})$} & $<90$ & $231(56.3 \%)$ & $179(43.7 \%)$ & & \\
\hline & $\geq 90$ & $87(46.0 \%)$ & $102(54.0 \%)$ & 5.521 & $0.019^{*}$ \\
\hline \multirow[t]{4}{*}{$\mathrm{SBP}(\mathrm{mmHg})$} & $<140$ & $161(51.1 \%)$ & $154(48.9 \%)$ & & \\
\hline & $\geq 140$ & $157(55.3 \%)$ & $127(44.7 \%)$ & 1.043 & 0.307 \\
\hline & $<160$ & $273(55.0 \%)$ & $223(45 \%)$ & & \\
\hline & $\geq 160$ & $45(43.7 \%)$ & $58(56.3 \%)$ & 4.412 & $0.036^{*}$ \\
\hline \multirow{2}{*}{ Diabetes } & Yes & $54(42.5 \%)$ & $73(57.7 \%)$ & & \\
\hline & No & $264(55.9 \%)$ & $208(44.1 \%)$ & 7.229 & $0.007^{*}$ \\
\hline \multirow[t]{2}{*}{$\mathrm{CHD}$} & Yes & $72(55.4 \%)$ & $58(44.6 \%)$ & & \\
\hline & No & $246(52.5 \%)$ & $223(47.5 \%)$ & 0.351 & 0.553 \\
\hline \multirow[t]{2}{*}{ Stroke } & Yes & $57(51.4 \%)$ & $54(48.6 \%)$ & & \\
\hline & No & $261(53.5 \%)$ & 227 (46.5\%) & 0.165 & 0.685 \\
\hline
\end{tabular}

The single factor analysis of $\mathrm{x}^{2}$ test

Abbreviations: ERD Early renal damage, BMI Body mass index, HD Hypertension duration, DBP Diastolic blood pressure, SBP Systolic blood pressure, CHD Coronary heart disease

${ }^{*} p<0.05$

Table 3 Results of binary logistic regression model analysis for predictors of ERD

\begin{tabular}{llll}
\hline Risk Factors & Odds Ratio & $\mathbf{9 5 \%} \mathbf{C l}$ & $\boldsymbol{P}$ \\
\hline Age $(\mathrm{y})$ & 1.468 & $1.179-1.829$ & $0.001^{*}$ \\
$\mathrm{HD}(\mathrm{y})$ & 1.230 & $0.963-1.570$ & 0.098 \\
$\mathrm{DBP}(\mathrm{mmHg})$ & 1.853 & $1.418-2.516$ & $<0.001^{*}$ \\
SBP $(\mathrm{mmHg})$ & 0.625 & $0.365-1.068$ & 0.086 \\
Diabetes & 2.031 & $1.334-3.092$ & $0.001^{*}$ \\
\hline
\end{tabular}

We performed a binary logistic regression analysis using SPSS software Abbreviations: ERD Early renal damage, $H D$ Hypertension duration, DBP Diastolic blood pressure, SBP Systolic blood pressure

${ }^{*} p<0.05$

of microalbuminuria [23]. In addition, DBP may better reflect peripheral resistance than mean SBP, as it was steadier than SBP when the subjects engaged in daily activities. Different age stages will make a large difference between DBP and SBP, just as DBP may better reflect peripheral resistance in relatively young people, while SBP may be associated with a predominance of arterial stiffness in old age [24].
The latest research has shown that there is a significant inverse association between $\mathrm{BP}$ and temperature; tighter $\mathrm{BP}$ control is more necessary in winter than in summer, especially in a colder climate [25]. The China Kadoorie Biobank study [25] verified that blood pressure varies seasonally, and each $10^{\circ} \mathrm{C}$ lower ambient temperature is associated with a $6.9 / 2.9 \mathrm{mmHg}$ higher SBP/DBP. Su et al. demonstrated that the detection and control of hypertension are down/up respectively when the temperature rises [26]. The HOMED-BP study suggested that the large-variation group (which increases significantly from winter to summer; systolic/diastolic $\geq 9.1 / \geq 4.5 \mathrm{mmHg}$ ) was confirmatory for major adverse cardiovascular events [27]. Anti-dipper hypertension is the chief hypertensive type in aged individuals; the management of nocturnal BP is especially critical. Notwithstanding, Hainan's warm, humid climate makes the area have little influence on night hypertension, and the tropical marine climate has an all-weather suitable temperature, with little significant change between day and night. Further, a light diet, sweat, and excessive salt excretion in Hainan may reduce ERD caused by hypertension. Currently, Chinese hypertension standard centres have been opened in many 


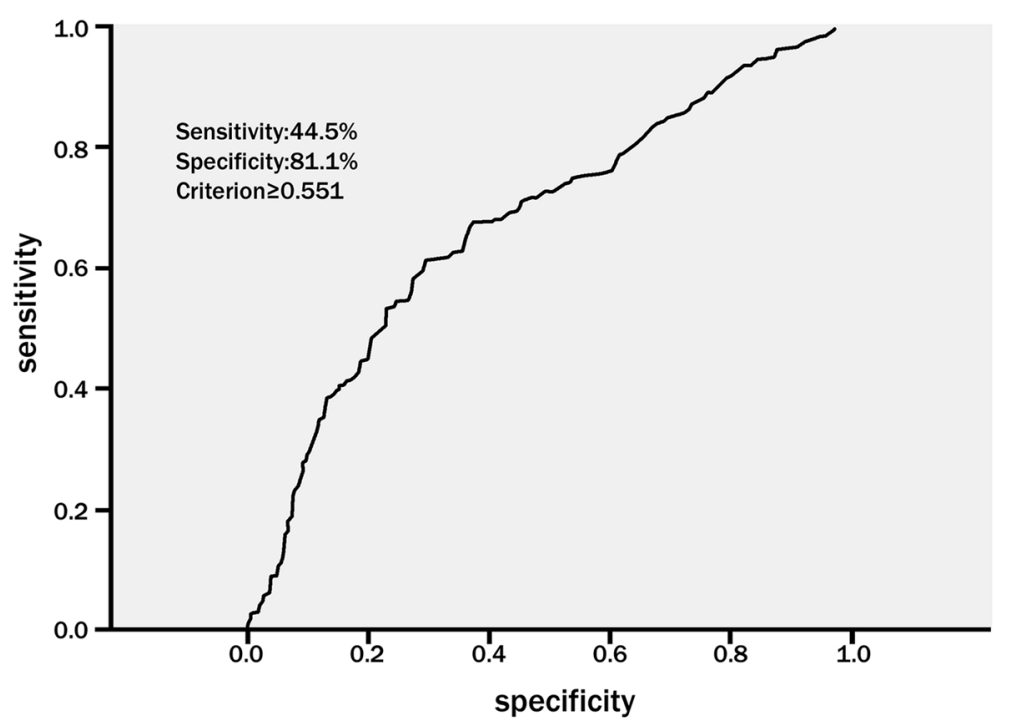

Fig. 5 ROC curve for the prediction of ERD through age, DBP and diabetes mellitus. Note: The area under the ROC curve was 0.677 (95\% Cl: $0.633-$ $0.720, p<0.001)$. The sensitivity and specificity of the optimal cut-off value were 44.5 and $81.1 \%$, respectively. Abbreviations: ROC, receiver operating characteristic; ERD, early renal damage; DBP, diastolic blood pressure

hospitals to reduce hypertensive target organ damage, which is a particularly important measure of Chinese chronic disease management. We found that advanced age ( $\geq 65$ years) is an independent risk factor for ERD. Ageing is an irreversible risk factor, and most elderly people adopt more sedentary lifestyles. A lack of exercise leads to weight gain. Thus, the prevalence of hypertension worldwide will continue to rise [28]. Advanced age should be given more attention regarding the stable control of blood pressure and the protection of target organs. A previous study implied that in patients aged $<60$ years, DBP provides significant value for predicting a morbid cardiovascular event [29]. Hence, how to delay senility and maintain the function of viscera remains a hot topic of research. Our results also signalled that control of $\mathrm{DBP}<90 \mathrm{mmHg}$ could be used for risk stratification of hypertensive patients without clinically significant renal damage. Recent evidence hints that UACR is a predictor of the development and progression of diabetes mellitus and cardiovascular disease [7, 9]. We also found that UACR is highly correlated with diabetes. However, our results indicated that both $\mathrm{CHD}$ and stroke have no significant differences compared to UACR. We think the reasons are that the favourable marine climate and a low salt and fat diet with seafood lead to delays in the progression of both diseases. Simultaneously, owing to Chinese chronic disease insurance, almost all patients with stage 3 hypertension can receive effective antihypertensive treatment. Above all, early monitoring of the index UACR, as well as control of blood glucose and DBP, can effectively delay EDR in patients with essential hypertension in the Chinese tropics.

\section{Limitations}

Anti-hypertensive drugs were not covered in this article.

\section{Conclusions}

Our findings imply that common medical comorbidities are associated with ERD in patients with essential hypertension in the Chinese tropics. Age, DBP, and diabetes are independent risk factors of ERD. Early monitoring of UACR, as well as control of blood glucose and DBP, can effectively delay EDR in patients with essential hypertension in the Chinese tropics.

\section{Abbreviations \\ UACR: Urine albumin/creatinine ratio; ERD: Early renal damage; HD: Hyperten- sion duration; SBP: Systolic blood pressure; DBP: Diastolic blood pressure; OR: Odds ratio; CKD: Chronic kidney disease; CHD: Coronary heart disease; LEU: Leukocyte; URO: Urobilinogen; ALB: Albumin; PRO: Protein; BIL: Bilirubin; GLU: Glucose; ASC: Ascorbic acid; SG: Specific gravity; KET: Ketone; NIT: Nitrite; CRE: Creatinine; BLO: Blood; CA: Calcium; BMI: Body mass index; Cl: Confidence interval; ROC: Receiver operating characteristic.}

\section{Acknowledgements}

Not applicable.

\section{Authors' contributions}

Yuzhuo Zhang, Wei Hao and Jike Li: research idea and study design; Chenglu Wei, Hira Aslam, Qingmin Feng, Qing Huang, Yongrong Li, Yu Zheng, Feifen Lv: data acquisition; Jike Li: statistical analysis; Yuzhuo Zhang, Ying Zhao, Jike Li: data and results interpretation; Jike Li: supervision and mentorship. Each author contributed important intellectual content during manuscript drafting or revision and accepts accountability for the overall work by ensuring that 
questions pertaining to the accuracy or integrity of any portion of the work are appropriately investigated and resolved. All authors approved the final version of the manuscript.

\section{Funding}

National Natural Sciences Foundation of China (81200150, 81660064), Hainan Province Natural Science Foundation (20158338), Hainan Provincial Foundation for Health Department (14A210227), Cultivating Fund of Hainan Medical University (HY2014-007), Educational Research Project of Hainan Medical University (HYZ201803), Student's Innovative Project of Hainan Medical University (X201911810074). The funder had no role in study design, data collection, analysis, reporting or the decision to submit for publication.

\section{Availability of data and materials}

The datasets generated and/or analyzed during the current study are available from the corresponding author.

\section{Declarations}

\section{Ethics approval and consent to participate}

All of the participants signed written informed consent before being interview, and the ethical committees of Hainan Medical University approved the study. All methods in this study were performed in accordance with the relevant guidelines and regulations. Written informed consent from the reported patient for publication was obtained.

\section{Consent for publication}

Not applicable.

\section{Competing interests}

The authors declare that they have no competing interests.

\section{Author details}

${ }^{1}$ First Affiliated Hospital of Hainan Medical University, Haikou, China. ${ }^{2}$ Marketing Department, Sanofi (Hangzhou), Haikou, China. ${ }^{3}$ Cardiovascular Department, Xi'an Hospital of Traditional Chinese Medicine, No.69, Fengcheng 8th Road, Weiyang District, Xi'an City 710021, Shaanxi Province, China.

Received: 14 October 2020 Accepted: 25 October 2021

Published online: 05 November 2021

\section{References}

1. Liu WJ, Wang LL, Huang XQ, He WC, Song ZW, Yang JW. Impaired orthostatic blood pressure stabilization and reduced hemoglobin in chronic kidney disease. J Clin Hypertens (Greenwich). 2019;21:1317-24. https:// doi.org/10.1111/jch.13658.

2. Wang Z, Chen Z, Zhang L, Wang X, Hao G, Zhang Z, et al. Status of hypertension in China: results from the China hypertension survey, 20122015. Circulation. 2018;137:2344-56. https://doi.org/10.1161/CIRCULATIO NAHA.117.032380.

3. Wang F, Yang C, Long J, Zhao X, Tang W, Zhang D, et al. Executive summary for the 2015 annual data report of the China kidney disease network (CK-NET). Kidney Int. 2019;95:501-5. https://doi.org/10.1016/j. kint.2018.11.011.

4. Yin LH, Yan WJ, Guo ZX, Zhou FZ, Zhang HY. Relation between blood pressure variability and early renal damage in hypertensive patients. Eur Rev Med Pharmaco Sci. 2017;21:2226-31.

5. Wouters OJ, O'Donoghue DJ, Ritchie J, Kanavos PG, Narva AS. Early chronic kidney disease: diagnosis, management and models of care. Nat Rev Nephrol. 2015;11:491-502. https://doi.org/10.1038/nrneph.2015.85.

6. Yadav D, Kang DR, Koh SB, Kim JY, Ahn SV. Association between urine albumin-to-creatinine ratio within the normal range and incident hypertension in men and women. Yonsei Med J. 2016;57:1454-60. https://doi. org/10.3349/ymj.2016.57.6.1454

7. Ren H, Wu C, Shao Y, Liu S, Zhou Y, Wang QY. Correlation between serum miR-154-5p and urinary albumin excretion rates in patients with type 2 diabetes mellitus: a cross-sectional cohort study. Front Med. 2020;16. https://doi.org/10.1007/s11684-019-0719-3.
8. Okubo A, Nakashima A, Doi S, Doi T, Ueno T, Maeda K, et al. High-normal albuminuria is strongly associated with incident chronic kidney disease in a nondiabetic population with normal range of albuminuria and normal kidney function. Clin Exp Nephrol. 2020;24:435-43. https://doi.org/10. 1007/s10157-019-01842-2.

9. Sung KC, Ryu S, Lee JY, Lee SH, Cheong E, Hyun YY, et al. Urine albumin/ creatinine ratio below $30 \mathrm{mg} / \mathrm{g}$ is a predictor of incident hypertension and cardiovascular mortality. J Am Heart Assoc. 2016;5:e003245. https:// doi.org/10.1161/JAHA.116.003245.

10. Kario K, Park S, Chia YC, Sukonthasarn A, Turana Y, Shin J, et al. 2020 Consensus summary on the management of hypertension in Asia from the HOPE Asia Network. J Clin Hypertens (Greenwich). 2020;22:351-62. https://doi.org/10.1111/jch.13751.

11. Cuspidi C, Ochoa JE, Parati G. Seasonal variations in blood pressure: a complex phenomenon. J Hypertens. 2012;30(7):1315-20. https://doi.org/ 10.1097/HJH.0b013e328355d7f9.

12. Stergiou GS, Palatini P, Kollias A, Kyriakoulis KG, Myers M, O'Brien E, et al. Seasonal blood pressure variation: a neglected confounder in clinical hypertension research and practice. Am J Hypertens. 2020;33(7):595-6. https://doi.org/10.1093/ajh/hpaa056.

13. Wang S, Li M, Hua Z, Ye C, Jiang S, Wang Z, et al. Outdoor temperature and temperature maintenance associated with blood pressure in 438,811 Chinese adults. Blood Press. 2017;26(4):246-54. https://doi.org/10.1080/ 08037051.2017.1297676.

14. Lavanderos MA, Cayun JP, Roco A, Sandoval C, Cerpa L, Rubilar JC, et al. Association study among candidate genetic polymorphisms and chemotherapy-related severe toxicity in testicular cancer patients. Front Pharmacol. 2019;10:206. https://doi.org/10.3389/fphar.2019.00206.

15. Abbott JH, Foster M, Hamilton L, Ravenwood M, Tan N. Validity of pain drawings for predicting psychological status outcome in patients with recurrent or chronic low back pain. J Man Manip Ther. 2015;23:12-9. https://doi.org/10.1179/2042618613Y.0000000046.

16. Kravets I, Mallipattu SK. The role of podocytes and podocyte-associated biomarkers in diagnosis and treatment of diabetic kidney disease. J Endocr Soc. 2020;4:bvaa029. https://doi.org/10.1210/jendso/bvaa029.

17. Cooper-DeHoff RM, Gong Y, Handberg EM, Bavry AA, Denardo SJ, Bakris GL, et al. Tight blood pressure control and cardiovascular outcomes among hypertensive patients with diabetes and coronary artery disease. JAMA. 2010;304:61-8. https://doi.org/10.1001/jama.2010.884.

18. Williams B, Mancia G, Spiering W, Agabiti Rosei E, Azizi M, Burnier M, et al. 2018 ESC/ESH guidelines for the management of arterial hypertension. Eur Heart J. 2018:39:3021-104. https://doi.org/10.1093/eurheartj/ehy339.

19. Franklin SS, Khan SA, Wong ND, Larson MG, Levy D. Is pulse pressure useful in predicting risk for coronary heart disease? The Framingham heart study. Circulation. 1999;100:354-60. https://doi.org/10.1161/01.cir.100.4. 354.

20. Franklin SS, Lopez VA, Wong ND, Mitchell GF, Larson MG, Vasan RS, et al. Single versus combined blood pressure components and risk for cardiovascular disease: the Framingham heart study. Circulation. 2009;119:24350. https://doi.org/10.1161/CIRCULATIONAHA.108.797936.

21. Lewington S, Clarke R, Qizilbash N, Peto R, Collins R. Age-specific relevance of usual blood pressure to vascular mortality: a meta-analysis of individual data for one million adults in 61 prospective studies. Lancet. 2002;360:1903-13. https://doi.org/10.1016/s0140-6736(02)11911-8.

22. Shahoud JS, Aeddula NR. Physiology, arterial pressure regulation. Treasure Island: StatPearls Publishing; 2020.

23. Kim D, Shim CY, Hong GR, Park S, Cho IJ, Chang HJ, et al. Impact of ambulatory blood pressure on early cardiac and renal dysfunction in hypertensive patients without clinically apparent target organ damage. Yonsei Med J. 2018;59:265-72. https://doi.org/10.3349/ymj.2018.59.2.265.

24. Filipovský J. Arterial hypertension in the elderly. Vnitr Lek. 2018;64:987-92.

25. Iwahori T, Miura K, Obayashi K, Ohkubo T, Nakajima H, Shiga T, et al. Seasonal variation in home blood pressure: findings from nationwide web-based monitoring in Japan. BMJ Open. 2018;8:e017351. https://doi. org/10.1136/bmjopen-2017-017351.

26. Su D, Du H, Zhang X, Qian Y, Chen L, Chen Y, et al. Season and outdoor temperature in relation to detection and control of hypertension in a large rural Chinese population. Int J Epidemiol. 2014;43:1835-45. https:// doi.org/10.1093/ije/dyu158.

27. Hanazawa T, Asayama K, Watabe D, Tanable A, Satoh M, Inoue R, et al. Association between amplitude of seasonal variation in self-measured 
home blood pressure and cardiovascular outcomes: HOMED-BP (hypertension objective treatment based on measurement by electrical devices of blood pressure) study. J Am Heart Assoc. 2018;7:e008509. https://doi. org/10.1161/JAHA.117.008509.

28. Collaboration NCD-RisC. Worldwide trends in blood pressure from 1975 to 2015: a pooled analysis of 1479 population-based measurement studies with 19.1 million participants. Lancet. 2017;389:37-55. https://doi.org/ 10.1016/S0140-6736(16)31919-5.

29. Khattar RS, Swales JD, Dore C, Senior R, Lahiri A. Effect of aging on the prognostic significance of ambulatory systolic, diastolic, and pulse pressure in essential hypertension. Circulation. 2001;104:783-9. https://doi. org/10.1161/hc3201.094227.

\section{Publisher's Note}

Springer Nature remains neutral with regard to jurisdictional claims in published maps and institutional affiliations.

- fast, convenient online submission

- thorough peer review by experienced researchers in your field

- rapid publication on acceptance

- support for research data, including large and complex data types

- gold Open Access which fosters wider collaboration and increased citations

- maximum visibility for your research: over $100 \mathrm{M}$ website views per year

At BMC, research is always in progress.

Learn more biomedcentral.com/submissions 